\title{
Erratum to Experimental frontiers for clinical applications: Novel approaches to understanding mechanisms of lymph node metastases in melanoma
}

\author{
Richard Essner
}

Published online: 10 July 2008

(C) Springer Science + Business Media, LLC 2008

The publisher regrets that the article, "Experimental frontiers for clinical applications: Novel approaches to understanding mechanisms of lymph Node metastases in melanoma," by Richard Essner, which appeared in Cancer and Metastasis Reviews 25:2, pp. 257-267 should not have published. Below please find the letter from the author:

Dear Drs. Raz and Honn,

I am writing to you to request that you retract my article entitled 'Experimental Frontiers for clinical applications: novel approaches to understanding the mechanisms of lymph node metastases in melanoma' from Cancer \& Metastasis Reviews. 25, 257 (2006).

This article is substantially similar, and in places identical, to one that was written by Dr Alistair Cochran and coauthors (and on which I was a coauthor) and which was already being processed for publication in Nature Reviews Immunology by Cochran, AJ, Huang, RR, Lee, J, Itakura, E, Leong, SP, and Esner, R. Tumour- induced immune modulation of sentinel lymph nodes Nature Rev. Immunol. 6, 659 (2006).

It was a mistake on my part to submit this article. In it I did not acknowledge the contribution of the principal author, Dr. Alistair Cochran, and his coauthors, and I submitted the review to CMR without their knowledge, which caused it to be under consideration simultaneously with the review already at NRI. These errors can be rectified by retraction of the CMR review.

Sincerely,

Richard Essner

The online version of the original article can be found at doi:10.1007/ s10555-006-8506-4.

\footnotetext{
R. Essner $(\bowtie)$

Department of Moleculer Therapeutics, John Wayne Cancer Institute,

2200 Santa Monica, CA 90404, USA

e-mail: Essner@jwci.org

R. Essner

Surgical Oncology and Molecular Therapeutics,

Houston, TX, USA
} 